\title{
Quantification of Acrylamide in Various Belgian Potato Products Using Solid Phase Extraction and Liquid Chromatography Tandem Mass Spectrometry Detection
}

\author{
Caroline Douny ${ }^{1, *}$, Joëlle Widart ${ }^{2}$, Guy Maghuin-Rogister ${ }^{1}$, Edwin De Pauw $^{2}$, Marie-Louise Scippo ${ }^{1}$ \\ ${ }^{1}$ University of Liège, CART (Center for Analytical Research and Technology), Analysis of Foodstuffs of Animal Origin, Faculty of \\ Veterinary Medicine, LIEGE, 4000, Belgium \\ ${ }^{2}$ University of Liège, CART (Center for Analytical Research and Technology), Mass Spectrometry laboratory, Faculty of Sciences, LIEGE, \\ 4000, Belgium
}

\begin{abstract}
Acry lamide $(\mathrm{CH} 2=\mathrm{CHCONH} 2)$, a neurotoxic and potentially carcinogenic substance for human health, is in the glare of the spotlights for a few years. This is mostly due to the fact that acrylamide was found worldwide in various heated foodstuffs. Levels reported in the literature vary from 25 to $2000 \mu \mathrm{g} / \mathrm{kg}$ and potato products are considered as containing the highest level in acrylamide. A possible pathway of synthes is of acry lamide is the Maillard reaction between reducing sugars and the amino acid asparagine. The aim of this study was to develop a liquid chromatography/mass spectrometry method to analyse as quickly as possible acrylamide in a variety of Belgian food samples such as potatoes, French fries, crisp bread, coffee, corn-flakes, etc. The sample preparation consisted in a liquid/liquid extraction, a centrifugation, followed by purification with Solid Phase Extraction (SPE). The instruments used were a Waters 2690 Alliance HPLC system coupled to a Micromass Quattro Ultima Platinum triple-quadrupole mass spectrometer. The analysis was performed in MS/MS mode using isotopic dilution technique for quantification. An internal 13C3 labelled standard was added prior to extraction. Quantification in MS/MS mode was calculated by reconstructing the ion current with the most abundant daughter ions for native and $13 \mathrm{C}$ labelled standard (ions of $\mathrm{m} / \mathrm{z} 55$ and 58 ).
\end{abstract}

Keywords Acrylamide, French Fries, Belgian Potato Products, SPE, LC-MS/MS

\section{Introduction}

Since the Swedish researchers put in evidence that there was a health problem with acrylamide (AA) being present in various common foodstuffs at high concentrations[1], acrylamide is among the "hot" topics in the analysts community.

In fact, acrylamide is a compound qualified as neurotoxic and "probably carcinogenic to humans" by the U.S. Environmental Protection Agency[2] and the International Agency for Research on Cancer (IARC)[3]. As it is mentioned in numerous articles, acrylamide present in food is formed at high temperatures by the reaction between amino acids and reducing sugars[4,5]. This reaction is also known as the Maillard reaction[4,6-8]. Heat-treated potato products (chips, French fries) are the products containing the highest amounts of acrylamide with approximately 2000 $\mu \mathrm{g} / \mathrm{kg}$ when the smallest amount is approximately $25 \mu \mathrm{g} / \mathrm{kg}$

* Corresponding author:

cdouny@ulg.ac.be (Caroline Douny)

Published online at http://journal.sapub.org/fph

Copyright (C) 2012 Scientific \& Academic Publishing. All Rights Reserved in coffee or bread. Different surveys have already been conducted in different countries showing that acrylamide is widely present in various foodstuffs [9-16]. In 2003, the Scientific institute of public health confirmed that acrylamide was also present on the Belgian market[17].

Since 2002, laboratories all over the world have begun settling analytical methods to detect that compound. Many different approaches have been explored but the most proposed methods were those using mass spectrometry (MS), either coupled to gas chromatography (GC)[18-21] and either to liquid chromatography (LC) [1,18-20,22-25]. There might be a drawback with GC because some GC-MS methods need a derivatization of acrylamide prior to the injection. With regard to the extraction, solid phase extraction (SPE) is the most widespread. However, Soxh let extraction[25] or Accelerated Solvent Extraction (ASE) $[26,27]$ are also used.

The purpose of the present work was to detect the presence of acrylamide in a variety of Belgian foodstuffs with a method using solid phase extraction and LC with tandem mass spectrometry (MS/MS). The sample preparation was modified from one provided during an acrylamide workshop at the Institute of Public Health in Brussels[28]. 
The optimisation of acrylamide detection and quantification by mass spectrometry will be pointed out below. So me parameters will be discussed such as collision gas pressure, LC column types, matrix-matched or standard calibration. Finally, results of Belgian foodstuffs study will show the overall content of acryla mide.

\section{Experimental}

\subsection{Che mic als and Material}

Acrylamide $(\mathrm{CH} 2=\mathrm{CHCONH} 2) \quad(99 \%$, electrophores is grade) and 13C-labelled acrylamide were purchased respectively from Sigma-Aldrich Corporation (St-Louis, MO, USA) and Cambridge Isotopes Laboratories (Andover, MA, USA). Formic acid (min 99\%) was from Acros Organics (New Jersey, USA). Hipersolv HPLC water and methanol were commercially available from $\mathrm{BDH}$ Laboratory supplies (Poole, England).

The filters purchased were hydrophilic single use syringe filters $(0.2 \mu \mathrm{m}$ pore size, Min isart) from Sartorius (Goettingen, Germany). $50 \mathrm{~mL}$ Falcon polypropylene graduated conical tube with cap we re co mmercially availab le from Greiner Bio-One (Germany). The solid-phase extraction (SPE) cartridges used were OASIS HLB $(6 \mathrm{~mL}$, LP $500 \mathrm{mg}$ packing) and Bond Elut - AccuCAT (3 mL, 200 mg packing), respectively fro $\mathrm{m}$ Waters corporation (Milford, MA, USA) and Varian Inc. (Harbor City, CA, USA).

\subsection{Instruments}

A 2690 Alliance Separation Modules (Waters, Milford, MA, USA) integrated autosampler, solvent delivery system and column heater coupled to a Quattro Ultima Platinum triple-quadrupole mass spectrometer (Micromass, Manchester, UK) were used for LC-MS-MS analysis.

\subsection{Standard Solutions}

Stock solutions of acrylamide (1 $\mathrm{mg} / \mathrm{mL})$ and 13C-labelled acrylamide $(10 \mu \mathrm{g} / \mathrm{mL})$, used as internal standard, were prepared by dissolving the compounds in methanol. All solutions were stored at $4^{\circ} \mathrm{C}$.

\subsection{Sample Preparation}

All samples (raw or fried) were then mixed with a Moulinex mixer (Germany). One gram of sample was weighed and transferred into a $50 \mathrm{~mL}$ polypropylene graduated conical tube with cap. Then, sample was spiked with internal standard to achieve a final concentration of $125 \mu \mathrm{g} / \mathrm{kg} 13 \mathrm{C}$-acrylamide. $10 \mathrm{~mL}$ of water were added. The solution was mixed a first time on a Vortex (high speed) during approximately one minute, then approximately 5 minutes on a rotating shaker.

The suspension was centrifuged $\left(3700 \mathrm{~g}, 15\right.$ minutes, $\left.5^{\circ} \mathrm{C}\right)$. If supernatant was still turbid, the centrifugation was repeated a second time. Then, $6 \mathrm{~mL}$ of the supernatant were filtered on a $0.20 \mu \mathrm{m}$ syringe filter before applying on solid phase extraction (SPE) cartridge.

For the SPE clean-up (see figure 1), the OASIS HLB SPE cartridge (Waters) was conditioned under vacuum with methanol $(5 \mathrm{~mL})$, and equilib rated with water $(5 \mathrm{~mL})$. Then, $5 \mathrm{~mL}$ of the filtered sample were loaded on the OASIS HLB SPE cartridge and the ext ract was allowed to pass comp letely through the sorbent material. The OASIS HLB SPE was washed with water $(2 \mathrm{~mL})$ and the extract was allowed to pass completely through the sorbent material. Then, the cartridge was eluted with $7.5 \mathrm{~mL}$ of methanol. The eluent was collected.

For the second step of the clean-up, the Bond Elut AccuCAT SPE cartridge (mixed-mode SPE column consisting of a strong cation exchange and a strong anion exchange sorbent packed into one bed, Varian Inc.) was conditioned under vacuum with $5 \mathrm{~mL}$ of methanol. Then, the Bond Elut AccuCAT SPE cartridge was loaded with the solution from the previous step and the eluent was collected directly.

The cartridge was rinsed with methanol $(1.5 \mathrm{~mL})$ which was combined with the eluent from the OASIS. The extract was then evaporated to dryness under $\mathrm{N} 2$ at $40^{\circ} \mathrm{C}$. Finally, $500 \mu \mathrm{L}$ of water were added and the solution was transferred into an injection vial.

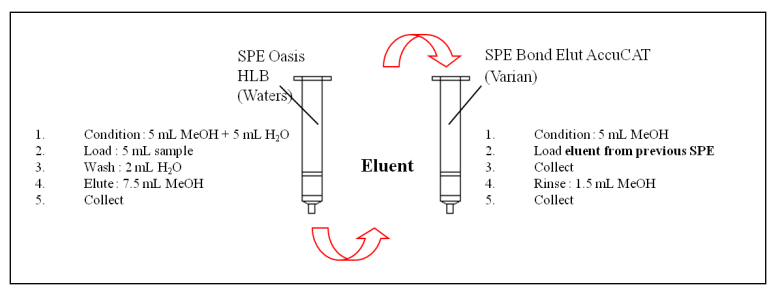

Figure 1. SPE clean-up

\subsection{LC-ES I-MS-MS}

For analytical separation, an Alltima $\mathrm{HP} \mathrm{C}_{18}$ amide column ( $250 \times 2.1 \mathrm{~mm}$ I.D., $3 \mu \mathrm{m}$, Altech, Deerfield, IL, USA) and Alltima HP C18HL (250 x $2.1 \mathrm{~mm}$ I.D., $3 \mu \mathrm{m}$, Alltech, Deerfield, IL, USA) were tested. The elution mode was isocratic using water with $0.1 \%$ acetic acid as LC solvent. The flow-rate was $0.2 \mathrm{~mL} / \mathrm{min}$ and the injection volume was $20 \mu \mathrm{L}$. The total run time was $8 \mathrm{~min}$. The column and samp les temperatures were set to $40^{\circ} \mathrm{C}$ and $10^{\circ} \mathrm{C}$, respectively.

Table 1. Acrylamide transitions $(\mathrm{m} / \mathrm{z})$ and their corresponding collision energies $(\mathrm{eV})$

\begin{tabular}{|c|c|c|}
\hline Compounds & Transitions $(\mathrm{m} / \mathrm{z})$ & Collision energy $(\mathrm{eV})$ \\
\hline \multirow{3}{*}{ Acrylamide ${ }^{12} \mathrm{C}_{3}$} & $72>55$ & 10 \\
\hline & $72>44$ & 30 \\
\hline & $72>27$ & 35 \\
\hline Acrylamide ${ }^{13} \mathrm{C}_{3}$ & $75>58$ & 10 \\
\hline
\end{tabular}

The mass spectrometer was operated in positive-ion mode, nitrogen as cone gas $(\sim 100 \mathrm{~L} / \mathrm{h})$ and desolvation gas ( 680 $\mathrm{L} / \mathrm{h})$. Argon was used as collision gas. The source and desolvation temperatures were set to 125 and $250{ }^{\circ} \mathrm{C}$, respectively. Multiple reaction monitoring (MRM) traces 
were acquired with the characteristic fragmentation transitions shown in Table 1.

The capillary and cone voltages were set to $3.2 \mathrm{kV}$ and 43 $\mathrm{V}$, respectively.

\subsection{Quantification}

Quantification was possible with isotopic dilution with acrylamide $13 \mathrm{C}$ as internal standard (125 ppb). A 6 point-curve in standard solutions was injected: $0,50,100$, 250, 500 and $1000 \mathrm{ppb}$.

\subsection{Potato Samples}

Samples used for optimising the method were purchased in different supermarkets in Liège, Belgium.

Then, the optimised method was applied to potato samples of different kinds provided by a specific Belgian industry: normal and "wavy" French fries, cube-shaped and sliced potatoes. Those samples (internal codes from 112 to 118) were prepared industrially with different amounts of sugar for the reason that they were destined for diverse countries.

All samp les were analysed before and after frying, which was realised in a deep fat fryer with beef tallow, at $180^{\circ} \mathrm{C}$. The fat used was analysed at three defined times: before first sample was fried, in the middle of the series of samples and after last sample.

Quality Controls (QC) have been realised with commercially available Belgian raw potatoes.

\section{Results and Discussion}

\subsection{Collision Gas Pressure}

In order to reach a good sensitivity for acrylamide, the collision gas pressure was optimized. Acrylamide is a low mass molecule so the fragmentation is difficult to be achieved with the traditional value of 2.5 10-3 mbar. Six injections of the same solution were done at five pressure values: $1.5 \times 10^{-3}, 7.5 \times 10^{-3}, 1.6 \times 10^{-2}, 3.1 \times 10^{-2}$ and $2.4 \times 10^{-2}$ mbar.

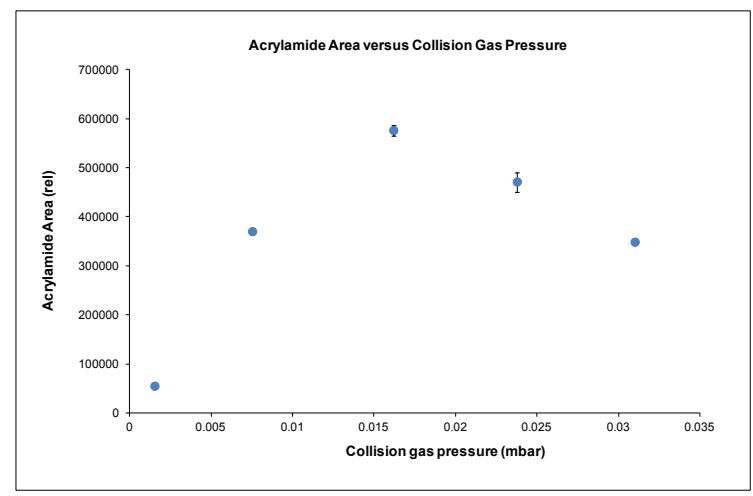

Figure 2. Acrylamide peak area (transition $72>55$ ) versus collision gas pressure (in mbar) $(\mathrm{n}=6$ for each pressure value, mean $\pm \mathrm{SD}$ )

Figure 2 shows the variation of signal with the collision gas pressure.
As it can seen on Figure 2, the best peak area for the transition $72>55$ is obtained for a collision gas pressure of $1.6 \times 10-2$ mbar. This is far from the values usually used in ESI-MS methods but this will assure a better response for acrylamide analys is.

\subsection{LC Columns}

Two different LC columns were tested (Alltech Alltima HP C18HL $3 \mu \mathrm{m}$ and Alltech Alltima HP C18 amide $3 \mu \mathrm{m}$ ) using the same solutions and analytical protocol. Tests were realised on raw potatoes spiked with a $250 \mathrm{ppb}$ acrylamide solution and $125 \mathrm{ppb}$ internal standard solution. The chromatograms obtained for acrylamide $12 \mathrm{C}$ and $13 \mathrm{C}$ are shown in Figure 3.

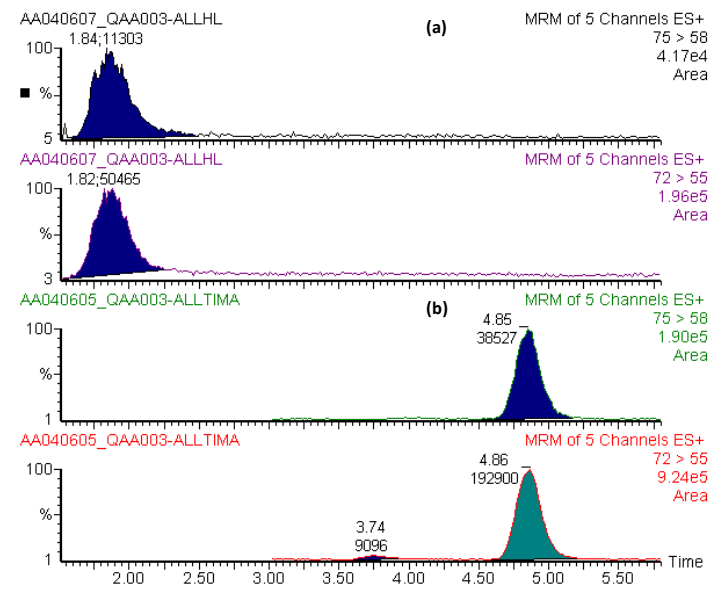

Figure 3. Acrylamide peaks eluated with (a) Alltech Alltima $\mathrm{HP} \mathrm{C18HL}$ $3 \mu \mathrm{m}$ column and (b) Alltech Alltima HP Cl 8 amide $3 \mu \mathrm{m}$ column

LC analysis realised with the amide column (b) gives better results than with the HL column (a), as well as for the area of the peaks than for their shape. What's more, the retention times are increased to 4.85 minutes with the amide column instead of 1.85 with the HL column.

\subsection{Matrix-Matched Calibration Versus Standard Calibr ati on}

In order to check matrix effects, we compared the results of a calibration curve realised with standards solutions at different concentrations with the results of raw potato samples spiked at different concentrations. Those samples were used as quality controls. The concentration of acrylamide (in ppb) versus the response is shown in Figure 4. The standard solutions and the spiked samples are represented by dots and triangles respectively. Figure 4 shows that the response obtained with each potato sample matches the values on the calibration curve realised with the standard solutions.

There is no significant difference between a calibration curve realised with or without matrix. From now, this will allow using curves realised without matrix and then the analys is will need less samples, less solvents and materials and therefore induce lower costs.

Limit of quantification (LOQ) has been established at 50 
$\mathrm{ppb}$ and limit of detection (LOD) at $25 \mathrm{ppb}$.

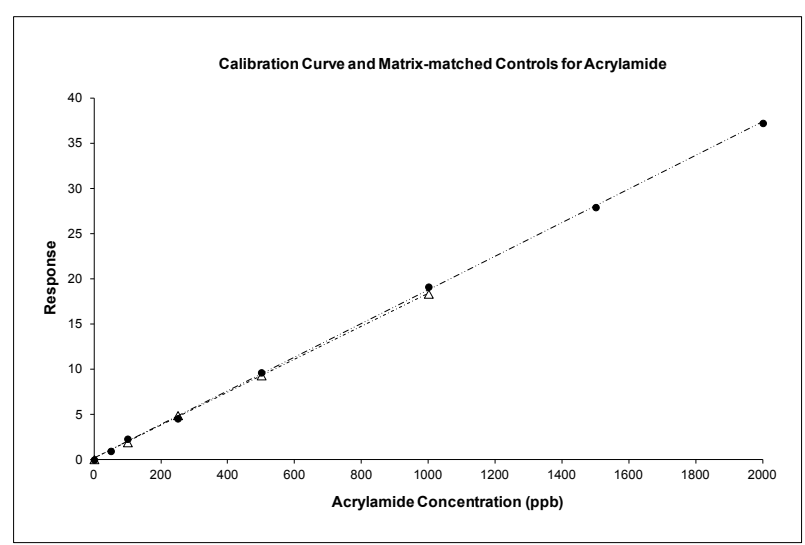

Figure 4. Comparison of a calibration curve (standard solutions) and raw potato samples spiked at different concentrations. (The standard solutions and the spiked samples are respectively represented by dots and triangles)

\subsection{Real Samples Study}

The optimised method was applied to potato samples. All of them were analysed before and after fry ing.

Results of the content in acrylamide detected in the potato samples are shown in Table 2.

The concentrations obtained are in concordance with the values found in literature.

What's more, the results of the three analyses of frying oil were all negative, meaning that the amount of acrylamide found in a sample is coming neither from potatoes previously fried, nor from the oil itself. It seemed that the quantity of sugar present in a variety of French fries is not correlated to the concentration of acrylamide formed during frying.

Table 2. Measured concentrations (in ppb) for potato samples 112 to 118 , before and after frying

\begin{tabular}{|c|c|c|c|}
\hline \multirow{2}{*}{$\begin{array}{l}\text { Internal } \\
\text { codes }\end{array}$} & \multirow{2}{*}{ Type of sample } & \multicolumn{2}{|c|}{$\begin{array}{l}\text { Measured values (ppb) } \\
\quad(\text { Mean, } n=2)\end{array}$} \\
\hline & & $\begin{array}{l}\text { Before } \\
\text { frying }\end{array}$ & $\begin{array}{l}\text { After } \\
\text { frying }\end{array}$ \\
\hline 112 & French fries & nd * & 1813 \\
\hline 113 & French fries & $<\mathrm{LOQ}$ & 1647 \\
\hline 114 & $\begin{array}{c}\text { « wavy » French } \\
\text { fries }\end{array}$ & $<\mathrm{LOQ}$ & 1827 \\
\hline 115 & $\begin{array}{c}\text { « wavy » French } \\
\text { fries }\end{array}$ & 295 & 1846 \\
\hline 116 & $\begin{array}{l}\text { « wavy » French } \\
\text { fries }\end{array}$ & $<\mathrm{LOQ}$ & 1409 \\
\hline 117 & Sliced potatoes & 546 & 2311 \\
\hline 118 & $\begin{array}{l}\text { Cube-shaped } \\
\text { potatoes }\end{array}$ & 202 & 2015 \\
\hline
\end{tabular}

* nd $=$ not detected $(<$ LOD $)$

\section{Conclusions}

A simple and rapid method for the quantification of acrylamide in a variety of foodstuffs has been developed. The optimisation was done focusing on the collision gas pressure and on the analytical column. This method has been tested with success on different Belgian products (potatoes, French fries, bread...).

\section{REFERENCES}

[1] J. Rosen, K.-E. Hellenas, "Analysis of acrylamide in cooked foods by liquid chromato graphy tandem mass spectrometry", Analyst, vol. 127, pp. 880-882, 2002.

[2] U.S. Environmental Protection A gency, "Chemical summary for acry lamide", in, U.S. Environmental Protection Agency, pp. 11, 1994.

[3] International Agency for Research on Cancer (IARC), in, International Agency for Research on Cancer (IARC), Lyon, pp. 389, 1994.

[4] D.S. Mottram, B.L. Wedzicha, A.T. Dodson, "Acry lamide is formed in the Maillard reaction", Nature, vol.419, pp. 448-449, 2002.

[5] R. Weisshaar, B. Gutsche, "Formation of acrylamide in heated potato products - model experiments pointing to asparagine as precursor", Deutsche Lebensmittel-Rundschau, vol. 98, pp.397-400, 2002.

[6] L.C. Maillard, "Action des acides aminés sur les sucres; formation des mélanoïdines par voie métabolique", C. R. Hebd. Séances Acad. Sci. 154, vol.66, 1912.

[7] D. Machiels, L. Istasse, "La réaction de Maillard: importance et applications en chimie des aliments."Annales de médecine vétérinaire, vol.146, pp.347-352, 2002.

[8] F. Shahidi, "Flavor of meat and meat products", Blackie Academic \& Professional, Glasgow, 1994.

[9] A. Claus, R. Carle, A. Schieber, "Acrylamide in cereal products: A review", Journal of Cereal Science, vol.47, pp. 118-133, 2008.

[10] O. Kaplan, G. Kaya, C. Ozcan, M. Ince, M. Yaman, "Acrylamide concentrations in grilled foodstuffs of Turkish kitchen by high performance liquid chromatography-mass spectrometry", Microchemical Journal, vol.93, pp.173-179, 2009.

[11] Y. Zhang, Y. Ren, H. Zhao, Y. Zhang, "Determination of acrylamide in Chinese traditional carbohydrate-rich foods using gas chromatography with micro-electron capture detector and isotope dilution liquid chromatography combined with electrospray ionization tandem mass spectrometry", Analytica Chimica Acta, vol.584, pp.322-332, 2007.

[12] H. Wang, A.W.M. Lee, S. Shuang, M.M.F. Choi, "SPE/HPLC/UV studies on acrylamide in deep-fried flour-based indigenous Chinese foods", Microchemical Journal, vol. 89, no.2, pp.90-97, 2008.

[13] R.C. Alves, C. Soares, S. Casal, J.O. Fernandes, M.B.P.P. Oliveira, "Acry lamide in espresso coffee: Influence of species, 
roast degree and brew length", Food Chemistry, vol.119, no.3, pp.929-934, 2009.

[14] P. Fohgelberg, J. Rosén, K.E. Hellenäs, L. Abramsson-Zetterberg, "The acrylamide intake via some common baby food for children in Sweden during their first year of life--an improved method for analy sis of acry lamide", Food and Chemical Toxicology, vol.43, no.6, pp.951-959, 2005.

[15] H. Mojska, I. Gielecinska, L. Szponar, M. Oltarzewski, "Estimation of the dietary acrylamide exposure of the Polish population", Food and Chemical Toxicology, vol.48, no.8-9, pp.2090-2096, 2010.

[16] M. Murkovic, "Acrylamide in Austrian foods", Journal of Biochemical and Biophysical Methods, vol.61, no.1-2, pp.161-167, 2004.

[17] Scientific institute of public health (ISP), "L'acry lamide dans les denrées alimentaires présentes sur le marché belge: une première série de mesures", in, Scientific institute of public health (ISP), Brussels, pp. 9, 2003.

[18] E. Tareke, P. Rydberg, P. Karlsson, S. Eriksson, M. Törnqvist, "Analysis of acrylamide, a carcinogen formed in heated foodstuffs", J. Agric. Food Chem., vol.50, pp.4998-5006, 2002.

[19] J.S. Ahn, L. Castle, D.B. Clarke, A.S. Lloyd, M.R. Philo, D.R. Speck, "Verification of the findings of acrylamide in heated foods", Food additives and contaminants, vol.19, no.12, pp.1116-1124, 2002

[20] H. Ono, Y. Chuda, M. Ohnishi-Kameyama, H. Yada, M. Ishizaka, H. Kobay ashi, M. Yoshida, "Analy sis of acry lamide by LC-MS/MS and GC-MS in processed Japanese foods", Food additives and contaminants, vol.20, no.3, pp.215-220, 2003.

[21] K. Kawata, T. Ibaraki, A. Tanabe, H. Yagoh, A. Shinoda, H Suzuki, A. Yasuhara, "Gas chromatographic-mass spectrometric determination of hydrophilic compounds in environmental water by solid-phase extraction with activated carbon fiber felt", Journal of Chromatography A, vol.911, pp.75-83, 2001.

[22] A. Becalski, B.P.-Y. Lau, D. Lewis, S.W. Seaman, "Acrylamide in foods: occurence, sources, and modeling", J. Agric. Food Chem., vol.51, pp.802-808, 2003.

[23] K.S. Leung, A. Lin, C.K. Tsang, S.T.K. Yeung, "Acrylamide in Asian foods in Hong Kong", Food additives and contaminants, vol.20, no.12, pp.1105-1113, 2003.

[24] S. Riediker, R.H. Stadler, "Analy sis of acry lamide in food by isotope-dilution liquid chromatography coupled with electrospray ionization tandem mass spectrometry", Journal of Chromatography A, vol.1020, no.1,pp.121-130, 2003.

[25] R. Medeiros Vinci, F. Mestdagh, B. De Meulenaer, "Acrylamide formation in fried potato products - Present and future, a critical review on mitigation strategies", Food Chemistry, vol.133, no.4, pp.1138-1154, 2011.

[26] J.R. Pedersen, J.O. Olsson, "Soxhlet extraction of acry lamide from potato chips", Analy st, vol.128, pp.332-334, 2003.

[27] F. Brandl, S. Demiani, J. Ewender, R. Franz, M. Gmeiner, L. Gruber, A. Gruner, M. Schlummer, S. Smolic, A. Störmer, G. Wolz, "A rapid and convenient procedure for the determination of acrylamide in foodstuffs", in, EJEAFChe, 2002.

[28] S. Cavalli, R. Maurer, F. Höfler, "Fast determination of acrylamide in food samples using accelerated solvent extraction (A SE) followed by IC with UV- or MS detection" in Proceedings of the 19th ICMS Symposium, Montreux, Switzerland, pp. 2, 2002.

[29] Y. Govaert, "Analyse d'acrylamide dans les denrées alimentaires par LC-MS/MS", Rapport du Workshop LNR, in, Scientific institute of public health (ISP), 2003.

[30] Commission Decision 2002/657/EC of August 12, in Journal Officiel des Communautés Européennes, European Commission, pp. 29, 2002.

[31] Council Directive 96/23/EC of 29 April 1996, in Official Journal of the European Union, European Commission, pp. $10,1996$. 